\title{
Apolipoprotein B detected in the plasma of a patient with homozygous hypobetalipoproteinaemia: implications for aetiology
}

\author{
G M B BERGER*, G BROWN*, H E HENDERSON*, AND F BONNICI $\dagger$ \\ From*the Department of Chemical Pathology and $\dagger$ the Department of Pediatrics, Red Cross War \\ Memorial Children's Hospital, Rondebosch, Cape, South Africa.
}

SUMMARY A hypobetalipoproteinaemic kindred is described in which the proband manifested the clinical and biochemical features of the homozygous state. Unlike the apparent complete absence of apolipoprotein B in the plasma of the five cases of homozygous hypobetalipoproteinaemia reported so far, we were able to demonstrate minute quantities of this protein (approximately $0.025 \%$ of normal) in the plasma of the proband. This finding suggests that the disorder may not result from a structural gene defect but may rather reflect a failure of secretion.

The homozygous state of the autosomal recessive condition abetalipoproteinaemia $\left(A B L P_{R}\right)$, and the autosomal dominant disorder hypobetalipoproteinaemia (HBLP), are both characterised by the apparent complete absence of apolipoprotein B (apoB) from the plasma. ${ }^{12}$ Homozygous HBLP is an extremely rare condition having been described in only five patients from four separate kindreds. ${ }^{3-6}$ Both ABLPR and homozygous HBLP manifest with similar plasma lipoprotein and lipid phenotypes and present with steatorrhoea, growth retardation, reduced plasma levels of the fat soluble vitamins, and anaemia characterised by abnormal red blood cell morphology, notably acanthocytosis. ${ }^{12} 7$ The two disorders are principally distinguished by the presence of normal levels of containing lipoproteins in the plasma of obligate heterozygotes for $A B L P_{R}$, in contradistinction to the reduced levels present in heterozygotes for HBLP, and by the relative absence of severe ocular and neuromuscular pathology in homozygous HBLP.

The distinctive modes of inheritance and the differing clinical presentation of the two syndromes imply that a different molecular defect underlies each disorder. In a recent report on a normotriglyceridaemic variant of $A B L P_{R}$, in which the liver form of apoB (apoB-100) was absent, Malloy et $\mathrm{al}^{8}$ suggested that HBLP is probably the result of a structural gene defect. In this paper we report a fifth hypobetalipoproteinaemic kindred in which the proband presented with the clinical and biochemical

Received for publication 2 June 1982.

Accepted for publication 30 October 1982. features of homozygous HBLP. The presence of minute amounts of immunoreactive and electrophoretically normal apoB detected in the plasma of this patient suggests that hypobetalipoproteinaemia may be the result of a regulatory or secretory abnormality rather than a structural gene defect.

\section{Case report}

The proband, a female weighing $3 \mathrm{~kg}$ at birth, was of mixed Malay-Coloured parentage. Pregnancy and labour were uneventful and she was breast fed initially. Symptoms of recurrent vomiting, diarrhoea, and failure to thrive were present within the first few months and frequent episodes of urticaria, bronchospasm, and respiratory infections also occurred. Despite dietary advice and supplementation, the above features persisted and were associated with intermittent abdominal distension. The patient's haemoglobin level varied from 8.6 to $13 \cdot 1 \mathrm{~g} / \mathrm{dl}$. Reticulocyte counts were generally raised ( 2 to $10 \%$ ), and anisocytotic, poikilocytotic, hypochromic, and crenated red blood cells were reported. Leucocytosis and eosinophilia were also frequently present but repeated investigations for intestinal parasites were negative, except for the finding of Giardia ova in the stool on one occasion. At the age of 1.4 years general osteopenia, distension of the bowel, and thickening of the bowel wall were noted on radiographs. Despite continued ill health and failure to thrive, with height and weight well below the 5th centile, the patient's albumin and immunoglobulin levels were essentially normal throughout. At the age of $3 \cdot 5$ years a routine 
blood chemistry yielded a cholesterol value of $0.57 \mathrm{mmol} / \mathrm{l}(22 \mathrm{mg} / \mathrm{dl})$. Further investigations were instituted to establish the precise diagnosis in the proband and to define the pattern of inheritance in the kindred.

\section{Materials and methods}

Lipid and lipoprotein studies were carried out on venous blood collected, after an overnight fast, into tubes containing trisodium-EDTA $(1 \mathrm{mg} / \mathrm{ml})$. Plasma cholesterol was measured by a single step enzymatic method (Boehringer Mannheim GmbH, catalogue number 1483 93) and plasma triglyceride was also determined using a commercial kit (Boehringer Mannheim $\mathrm{GmbH}$, catalogue number 124032). High density lipoprotein-cholesterol (HDL-C) was determined after heparin-manganese precipitation of the apoB containing lipoproteins, ${ }^{910}$ and low density lipoprotein-cholesterol (LDL-C) was calculated according to the formula proposed by Friedewald et al. ${ }^{11}$ Plasma phospholipids were assayed according to Kates. ${ }^{12}$ Lipoproteins were subjected to electrophoresis on cellulose acetate membranes and stained with Oil Red 7B.

$A p o B$ and apoA in plasma from the proband and her mother were sought using standard methods of immunoelectrophoresis and double immunodiffusion. Antibodies were obtained from Behringwerke AG Marburg and plasma or lipoprotein fractions were concentrated four- to five-fold to improve detection. These experiments failed to reveal the presence of apoB in the proband and efforts were made to concentrate the $d<1.063 \mathrm{~g} / \mathrm{ml}$ lipoprotein fraction further before polyacrylamide gel electrophoresis ${ }^{13}$ or electroimmunophoresis using the Laurell technique. ${ }^{14}$ Specifically, $50 \mathrm{ml}$ of blood was collected into tubes containing EDTA $(1 \mathrm{mg} / \mathrm{ml}$ blood) and centrifuged immediately to obtain the plasma to which the following preservatives were then added: penicillin $30 \mathrm{mg} / 100 \mathrm{ml}$, streptomycin $5 \mathrm{mg} / 100 \mathrm{ml}$, dithiothreitol $50 \mathrm{mg} / 100 \mathrm{ml}$, sodium azide $20 \mathrm{mg} / 100 \mathrm{ml}$, phenylmethylsulfonyl fluoride $0.6 \mathrm{mmol} / \mathrm{l}$, and $\varepsilon$-aminocaproic acid $130 \mathrm{mg} / 100 \mathrm{ml}$. A total of $25 \mathrm{ml}$ of plasma was over-layered with $\mathrm{KBr}(\mathrm{d}=1.063 \mathrm{~g} / \mathrm{ml})$ containing the above preservatives and $15 \mathrm{mg} / 100 \mathrm{ml}$ EDTA and centrifuged at $27000 \mathrm{rpm}$ for 26 hours in a Beckman L5-65 ultracentrifuge using a SW27 rotor. The supernatant $\mathrm{d}<1.063 \mathrm{~g} / \mathrm{ml}$ lipoproteins were recovered by tube slicing, then resuspended in $\mathrm{KBr}$, and washed through the same solution at $42000 \mathrm{rpm}$ for 16 hours in an SW50.1 rotor. A final volume of $0.7 \mathrm{ml}$ was collected by tube slicing and dialysed against $0.019 \mathrm{~mol} / \mathrm{l}$ sodium chloride containing a diluted mixture of the above preservatives.
Before polyacrylamide electrophoresis, delipida $\stackrel{\mathbb{D}}{\stackrel{D}{D}}$ tion was carried out by shaking $0.5 \mathrm{ml}$ of the dialysed: lipoprotein fraction with $5 \mathrm{mg}$ sodium dodecy 5 sulfate and $1 \mathrm{ml}$ of a $40: 60$ butanol/diisopropy 6 ether (DIPE) mixture. After centrifugation the aqueous layer was washed with $1 \mathrm{ml}$ DIPE to removen the butanol and $0.3 \mathrm{ml}$ of the mixture was furthero concentrated to $60 \mu \mathrm{l}$ under a gentle stream of dryo nitrogen gas. To the $60 \mu$ l of sample was added $50 \mu \mathrm{l}$ of buffer $(50 \mathrm{mmol} / \mathrm{l}$ Tris $\mathrm{HCl}, \mathrm{pH} 6 \cdot 8 \overrightarrow{\mathrm{O}}$ containing $20 \mathrm{~g} / 100 \mathrm{ml}$ glycerol and $5 \mathrm{~g} / 100 \mathrm{~mL}$ B-mercaptoethanol); $80 \mu \mathrm{l}$ of the mixture was applied to a polyacrylamide gradient gel and electro phoresed at $70 \mathrm{~V}$ for 16 hours. The above procedurep was performed on two separate samples of plasmis with an intervening interval of 6 months. Great carew was taken to ensure that no extraneous apoB ${ }_{0}^{\circ}$ contamination occurred, especially on the seconde occasion. The final aliquot applied thus represented the total apolipoprotein content of the $d<1.063^{-}$ $\mathrm{g} / \mathrm{ml} \mathrm{LP}$ fraction from $11 \mathrm{ml}$ plasma, ignoring non-specific losses incurred during the procedure $\overparen{\Phi}$ The same lipoprotein fraction obtained, afterco previous removal of chylomicrons, from $4 \mathrm{ml}$ plasmo from non-fasting, normolipaemic control subjects was isolated using essentially similar procedures The amount of apolipoprotein, however, finally applied to the gel represented that derived from onlyo $5.6 \mu \mathrm{l}$ of the original plasma. For purposes of immunochemical detection the $\mathrm{d}<1.063$ fraction was isolated by ultracentrifugation as above, but without $\overrightarrow{\vec{b}}$ washing. The six times concentrated ultracentrifuga $P$ fraction was dialysed overnight against Tris- $\mathrm{HCl}, \mathrm{pH}$ $7 \cdot 4$, and an aliquot was concentrated a further 34-fold by means of ultrafiltration and dialysis (Micro $\overline{3}$ ProDiCon, Bio-Molecular Dynamics, Oregon). OP this, $3 \mu 1$ were applied directly to the well of an agarose gel plate $(108 \mu \mathrm{l}$ of apoB antiserum in $15 \mathrm{~m} \vec{b}$ of $0.75 \%$ agarose gel). Since we usually dilute whole plasma 15 -fold for apoB assay by electroimmunophoresis, the $d<1.063$ fraction from the proband was therefore concentrated 3060 times $(6 \times 34 \times 15$ 男 relative to normal plasma. To check specificity? $1.080<\mathrm{d}<1.25$ lipoprotein fractions from the proband and from a normal control were also run The sensitivity was ascertained by diluting $\mathrm{d}<1.063$ lipoprotein fraction of normal plasma 1200 times and 2400 times before being processed ir the same way as plasma from the proband. Smale 'rockets' were seen with both these dilutions whereas the $1.080<\mathrm{d}<1.25$ fraction from a normal subject $t^{+}$ failed to react with antiserum.

The viscosity of whole blood and plasma was determined by means of a core/plate viscomete? (Wells-Brookfield Microviscometer, Stoughton\& Mass) according to the manufacturer's instructions? 


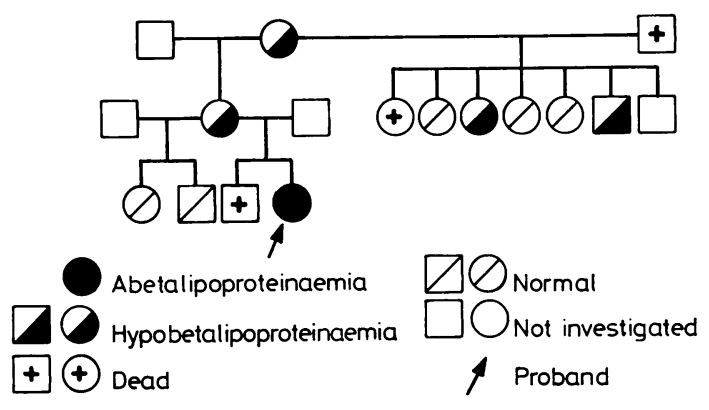

FIG 1 Pedigree of kindred.

Values on whole blood were corrected for haematocrit and were expressed in centipoise (cps). Other laboratory investigations were carried out using standard procedures.

\section{Results}

\section{FAMILY STUDIES}

Plasma lipid and lipoprotein concentrations were measured in most of the available family members (table, fig 1). The mother of the proband was not married to the alleged biological father who denied parenthood and refused investigation. There was no history of consanguinity. The mother, maternal grandmother, a maternal half-aunt, and maternal half-uncle showed reduced LDL-C and low plasma cholesterol levels. Phospholipid levels were low in the mother and maternal grandmother. Plasma triglyceride values were occasionally low-normal in affected family members but could not be obviously distinguished from the unaffected relatives. Plasma HDL-C concentrations were unremarkable.

LIPID AND LIPOPROTEIN STUDIES ON THE PROBAND

The proband manifested total absence of LDL-C and markedly diminished plasma cholesterol, triglyceride, and phospholipid concentrations which did not overlap with those of her affected relatives (table 1). Her plasma HDL-C levels were low to low-normal. A breakfast loaded with liberal quantities of cream failed to elicit any significant increase in her post-prandial lipid values: basal levels, $0.85 \mathrm{mmol} / 1(33 \mathrm{mg} / 100 \mathrm{ml})$ cholesterol and $0.27 \mathrm{mmol} / \mathrm{l}(24 \mathrm{mg} / 100 \mathrm{ml})$ triglyceride; 2 hour levels, $0.72 \mathrm{mmol} / \mathrm{l}(28 \mathrm{mg} / 100 \mathrm{ml})$ cholesterol and $0.31 \mathrm{mmol} / 1(27 \mathrm{mg} / 100 \mathrm{ml})$ triglyceride; 4 hour levels, $0.72 \mathrm{mmol} / 1(28 \mathrm{mg} / 100 \mathrm{ml})$ cholesterol and $0.19 \mathrm{mmol} / \mathrm{l}(17 \mathrm{mg} / 100 \mathrm{ml})$ triglyceride.

Lipoprotein electrophoresis performed at the age of 4 years showed an alpha migrating lipid fraction only. On centrifuging the patient's fasting plasma at $19000 \mathrm{rpm}$ for $2 \cdot 5$ hours in the 40.3 rotor of a Beckman model L5-65 ultracentrifuge, traces of a creamy substance were obtained in the supernatant. ApoB was undetectable in a plasma sample from the proband concentrated five-fold by ultrafiltration (fig 2a), but was clearly present in her mother (fig $2 b)$. On cellulose acetate electrophoresis of plasma obtained from the proband at the age of 8 years a small amount of lipid staining material was observed migrating in the prebeta region (fig 3), and, on another occasion, a distinct band was present at the origin. Once again immunoelectrophoresis and double immunodiffusion failed to reveal the presence of apoB in the plasma, even when concentrated approximately four-fold by ultracentrifugation. ApoA was immunochemically detectable in approximately normal quantities in the plasma of the proband and her mother.

On two separate occasions, at the age of 8 and 9 years, polyacrylamide gel electrophoresis of the $\mathrm{d}<1.063$ lipoprotein fraction of the proband, carried out as described under Methods, revealed the presence of a protein fraction co-migrating with

TABLE Lipid and lipoprotein levels in the kindred.

\begin{tabular}{|c|c|c|c|c|c|c|}
\hline Case & $\begin{array}{l}\text { Age } \\
(y r)\end{array}$ & $\begin{array}{l}\text { Total plasma } \\
\text { cholesterol } \\
(\mathrm{mmol} / \mathrm{l})\end{array}$ & $\begin{array}{l}\text { Plasma } \\
\text { triglyceride } \\
(\mathrm{mmol} / \mathrm{l})\end{array}$ & $\begin{array}{c}H D L-C \\
(\mathrm{mmol} / \mathrm{l})\end{array}$ & $\begin{array}{l}L D L-C \\
(\mathrm{mmol} / \mathrm{l})\end{array}$ & $\begin{array}{l}\text { Plasma } \\
\text { phospholipid } \\
(\text { mmol/l) }\end{array}$ \\
\hline Proband & $3 \cdot 5-8 \cdot 0$ & $\begin{array}{l}0.83^{*} \\
(0.62-0.99)\end{array}$ & $\begin{array}{l}0.27^{*} \\
(0.23-0.32)\end{array}$ & $\begin{array}{l}0.82 \\
(0.72-0.91)\end{array}$ & $\begin{array}{l}0^{*} \\
(0-0 \cdot 02)\end{array}$ & $\begin{array}{l}0.62^{*} \\
(0.61-0.63)\end{array}$ \\
\hline Half-brother & 3 & 3.48 & 1.03 & 0.91 & $2 \cdot 10$ & $2 \cdot 74$ \\
\hline Half-sister & 5 & $3 \cdot 52$ & 0.40 & $1 \cdot 35$ & 1.99 & $2 \cdot 26$ \\
\hline Mother & $32-35$ & $\begin{array}{l}2 \cdot 29^{*} \\
(2 \cdot 20-2 \cdot 40)\end{array}$ & $\begin{array}{l}0.53 \\
(0.29-0.76)\end{array}$ & $\begin{array}{l}1 \cdot 27 \\
(0 \cdot 93-1 \cdot 22)\end{array}$ & $\begin{array}{l}0.77^{*} \\
(0.43-1 \cdot 14)\end{array}$ & $\begin{array}{l}1 \cdot 56^{*} \\
(1 \cdot 52 ; 1 \cdot 61)\end{array}$ \\
\hline $\begin{array}{l}\text { Maternal } \\
\text { grandmother }\end{array}$ & 48 & $\begin{array}{l}3 \cdot 18^{*} \\
(3 \cdot 08 ; 3 \cdot 28)\end{array}$ & $\begin{array}{l}1 \cdot 58 \\
(1 \cdot 55 ; 1 \cdot 62)\end{array}$ & $\begin{array}{l}1 \cdot 14 \\
(1 \cdot 05 ; 1 \cdot 23)\end{array}$ & $\begin{array}{l}1 \cdot 33^{*} \\
(1 \cdot 29 ; 1 \cdot 37)\end{array}$ & $1 \cdot 18^{*}$ \\
\hline half-aunt & 7 & 4.83 & 1.00 & $1 \cdot 30$ & 3.07 & - \\
\hline half-aunt & 12 & $2 \cdot 51^{*}$ & 0.46 & $1 \cdot 55$ & $0.75^{*}$ & - \\
\hline half-aunt & 13 & $3 \cdot 24$ & 0.45 & $1 \cdot 29$ & $1 \cdot 74$ & - \\
\hline half-aunt & 15 & 3.78 & 0.71 & $1 \cdot 33$ & $2 \cdot 12$ & - \\
\hline half-uncle & 20 & $2 \cdot 52 *$ & 0.86 & $1 \cdot 16$ & $0.97^{*}$ & 一 \\
\hline
\end{tabular}

*Values below 5 th centile of age adjusted normal range. SI conversion factors from mmol $/ 1$ to $\mathrm{mg} / \mathrm{dl}: \mathrm{cholesterol} \times 38 \cdot 7$; triglyceride $\times 88 \cdot 5$; phospholipid $\times 77 \cdot 5$. 

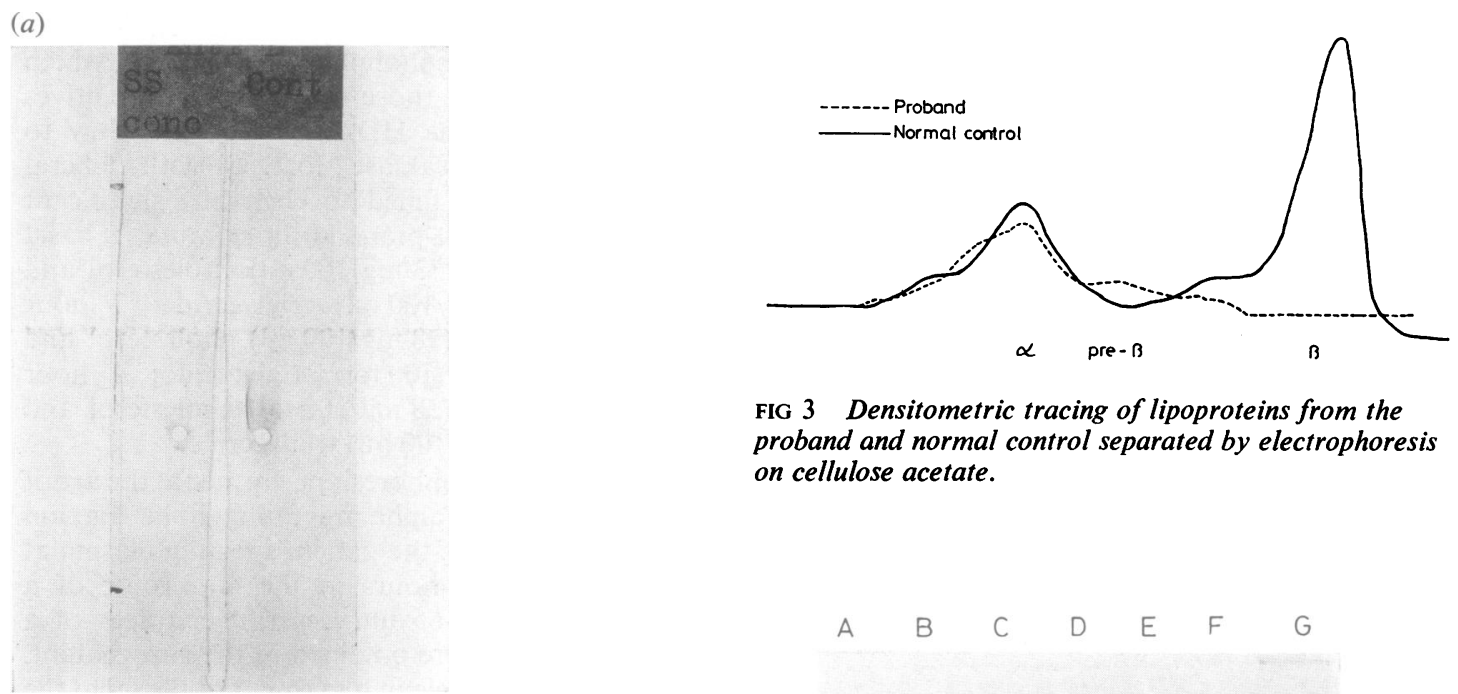

(b)

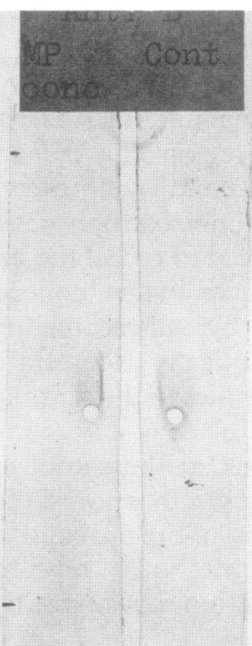

FIG 2 (a) Immunoelectrophoresis of plasma from proband and healthy subject (cont) against anti-apoB antibody. Plasma from proband was concentrated 5-fold by ultrafiltration before application. (b) Immunoelectrophoresis of plasma from mother of proband and healthy subject (cont) against anti-apoB antibody. Plasma from mother was concentrated 5-fold by ultrafiltration.

normal apoB (fig 4). A number of other bands were also apparent on the strip. One heavy band was in the same position as apoE while two further bands were roughly co-migratory with the apoC peptides. Resolution was poor in that region of the gel and no attempt was made to identify the $C$ peptides further. The presence of immunoreactive apoB in plasma from the proband was confirmed by means

FIG 3 Densitometric tracing of lipoproteins from the proband and normal control separated by electrophoresis on cellulose acetate.

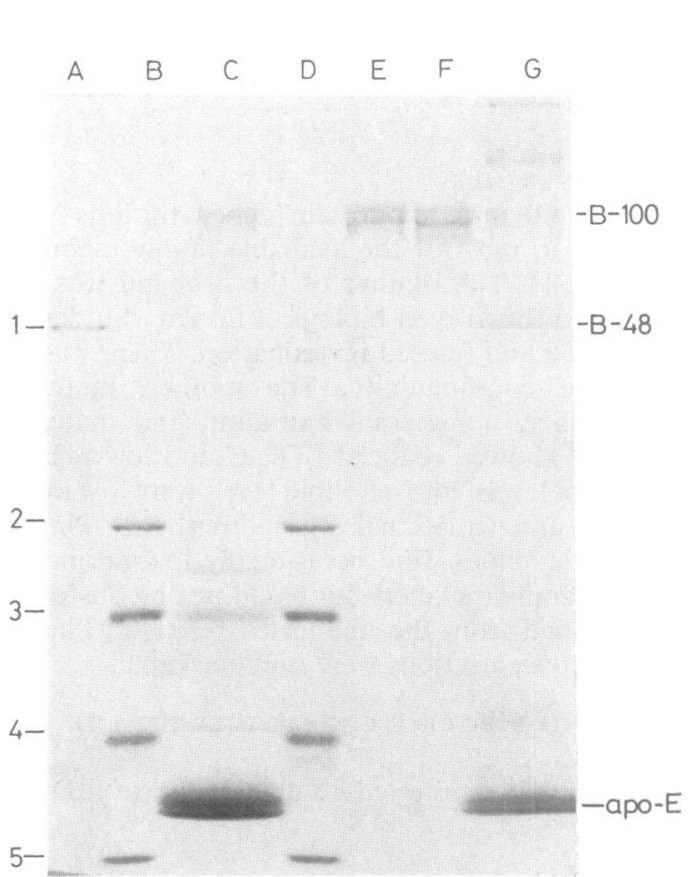

FIG 4 Polyacrylamide gel electrophoresis of plasma lipoprotein fraction from proband and control subject. Lanes $A, B$, and D: molecular weight standards, Ferritin subunit, Mr 220 000; phosphorylase b, Mr 94000 ; albumin, Mr 67000 ; ovalbumin, Mr 43 000; carbonic anhydrase, Mr 30000 (Pharmacia Fine Chemicals AB, Uppsala, Sweden). Lane C: apolipoproteins of plasma fractions $d<1.063$ from proband prepared as given under Methods. Lanes E and F: apolipoproteins of plasma fraction d=1.006-1.063 $\mathrm{g} / \mathrm{ml}$ from control subject. Lane G: apolipoproteins of chylomicron fraction (plasma centrifuged for $30 \mathrm{~min}$ at $14500 \mathrm{rpm}$ in SW 27 rotor) from a control subject.

$B-100$, apoB $M r=549000 ; B-48, a p o B M r=264000$. Terminology according to Kane et al. ${ }^{20}$ 


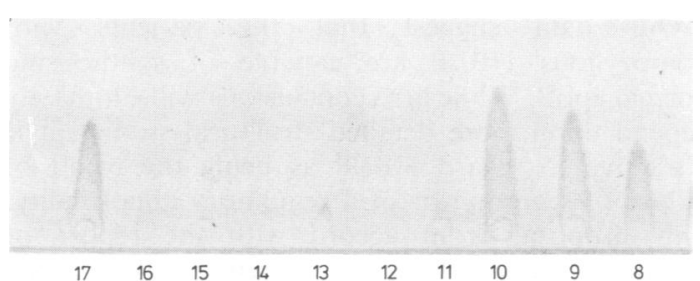

FIG 5 Electroimmunophoresis of lipoprotein fractions from proband and control subjects. See Methods for technical details.

No 8, 9, 10: frozen low density lipoprotein pool appropriately diluted. No $11,12,15,16: d<1.063 \mathrm{~g} / \mathrm{ml}$ lipoprotein fraction from proband. No 13, 14: diluted $(1200 x$ and $2400 x) d<1.063 \mathrm{~g} / \mathrm{ml}$ lipoprotein fraction from control subject. No 17: normal whole plasma diluted $1 / 15$.

of electroimmunophoresis (fig 5) of the $d<1.063$ $\mathrm{g} / \mathrm{ml}$ fraction concentrated 3060 -fold. Interestingly, a small amount of apoB immunoreactive material was also found in the concentrated $1.080<\mathrm{d}<1.25$ fraction from the proband but was absent, as expected, from the same fraction obtained from normal plasma.

\section{RESPONSE TO TREATMENT}

The proband was placed on a low fat intake supplemented with medium chain triglyceride, vitamin A (5000 mg/day), vitamin $\mathrm{K}(10 \mathrm{mg} /$ day $)$, and vitamin E (400 to $1200 \mathrm{mg} /$ day). Compliance has been variable but the vomiting and diarrhoea ceased. Faecal fat excretion, which was high when measured initially $(35 \mathrm{mmol} /$ day, normal $\leqslant 19$ $\mathrm{mmol} /$ day), was normal when measured on three subsequent occasions. Plasma vitamin E concentration measured during a period of non-compliance was $2.8 \mu \mathrm{g} / \mathrm{ml}$. After supplementation for 1 week the plasma level rose to $6.0 \mu \mathrm{g} / \mathrm{ml}$ (normal range 8.3 to $15.4 \mu \mathrm{g} / \mathrm{ml}$ ). Plasma alkaline phosphatase, which had been low initially ( $44 \mathrm{U} / 1$, normal range 70 to $150 \mathrm{U} / \mathrm{l})$, also increased to $129 \mathrm{U} / 1$ by the age of 6.5 years. The plasma carotene level was low $(33 \%$ of normal mean) shortly after diagnosis and has not been reassayed. Other routine biochemical investigations were normal except for a slightly reduced plasma magnesium on one occasion $(0.64 \mathrm{mmol} / 1$, normal range 0.70 to $0.95 \mathrm{mmol} / \mathrm{l}$ ).

The patient's haemoglobin levels have varied between $8 \cdot 2$ and $10 \cdot 8 \mathrm{~g} / \mathrm{dl}$. Acanthocytosis has been repeatedly demonstrable on both wet and dry preparations. Reticulocytosis also persisted but was slightly diminished relative to values before the institution of treatment. Osmotic fragility and autohaemolysis, carried out in saline with and without added glucose and ATP, were normal. The viscosity of whole blood, corrected for haematocrit, was $7.35 \mathrm{cps}$ at the age of 8 years. A reference range derived from 15 healthy adult subjects was 4.25 to $6.75 \mathrm{cps}$. Increased microviscosity of red cell membranes in abetalipoproteinaemic subjects has previously been reported. ${ }^{15}$ Whole blood viscosity in the mother of the proband was normal $(5.66 \mathrm{cps})$.

The patient's neurological and ophthalmological status was completely normal on careful clinical examination at the time of diagnosis and when last determined at the age of 9 years. Her peroneal nerve conduction rate $(53 \mathrm{~m} / \mathrm{s})$ and terminal latency period $(2.05 \mathrm{~m} / \mathrm{s})$ were also within normal levels at the age of 5 years, and at the age of $6 \cdot 3$ years her electroretinogram, visual evoked responses, and visual acuity were completely normal. The recurrent respiratory infections have ceased but growth has remained severely retarded ( $<3$ rd centile).

\section{Discussion}

The trait for hypobetalipoproteinaemia in this kindred is vertically transmitted through three maternal generations (fig 1), culminating in apparent abetalipoproteinaemia in the proband. All family members examined, apart from the proband, were in good health and acquired causes of hypobetalipoproteinaemia can be excluded. The frequency of familial hypobetalipoproteinaemia has been variously put at between 1 per $1000^{16}$ and 1 per $3000^{17}$ in unselected populations. These figures imply a general population incidence of one case per 4 to $36 \times 10^{6}$ for homozygous HBLP. Even in the absence of biochemical information on her biological father, it is reasonable to conclude that the proband represents the homozygous state in view of the repeated absence of apoB from her plasma by the usual methods, the markedly reduced total plasma cholesterol and phospholipid levels compared with her hypobetalipoproteinaemic maternal relatives, and the characteristic clinical presentation. It is not possible, however, to exclude the more remote chance of genetic heterogeneity, including double heterozygosity for ABLPR and HBLP.

The biochemical phenotype in homozygous HBLP is virtually indistinguishable from ABLP $P_{R}$. Both conditions are characterised by an apparent complete absence of apoB and the apoB containing lipoprotein fractions of $\mathrm{d}<1.063 \mathrm{~g} / \mathrm{ml}$. In the patients with homozygous HBLP reported so far, apoB has been undetectable by means of immunodiffusion and immunoelectrophoresis against both laboratory prepared $^{346}$ and commercial ${ }^{5}$ antibodies and by polyacrylamide gel electrophoresis. Cottrill et $a l^{4}$ used four- to six-fold concentrated plasma fractions to enhance the sensitivity of their procedures and Salt $e t a l^{3}$ claimed that the (unspecified) immuno- 
chemical technique employed by them could detect apoB at $1 / 1000$ of its normal plasma concentration. We failed to find apoB immunoreactivity in the proband's plasma on immunoelectrophoresis or double immunodiffusion capable of detecting apoB at a concentration of about $2 \%$ of normal.

Despite our negative findings, using relatively insensitive methods, and the failure of previous workers to detect apoB using comparable or more sensitive techniques, on polyacrylamide electrophoresis of a highly concentrated plasma fraction from the proband, we were able to visualise clearly a protein band co-migrating with normal apoB. In the procedure we finally adopted, the apolipoproteins derived from an approximately 2000-fold greater volume of plasma from the proband than from the control subject were applied to the gel (see Methods). Despite this discrepancy, visualisation of the stained bands (fig 4) revealed a two-fold greater intensity of the apoB band in the control strips. These observations imply that the concentration of apoB in the proband's plasma was about $0.025 \%$ of normal, or $0.02 \mathrm{mg} / 100 \mathrm{ml}$ assuming a normal plasma apoB concentration of $80 \mathrm{mg} / 100 \mathrm{ml} .^{18}$ The electrophoretic results were corroborated by detecting small, but definite, amounts of apoB immunoreactivity in a highly concentrated $\mathrm{d}<1.063$ lipoprotein fraction from the proband (fig 5). The presence of some apoB in the HDL $(1.080<d<1.25)$ fraction obtained from the proband was surprising, but could not be attributed to non-specificity since no reaction was seen using concentrated HDL from a healthy control. Since, by the time this analysis was performed, the $\mathrm{d}>1.063 \mathrm{~g} / \mathrm{ml}$ fraction from the proband had stood at $+4^{\circ}$ for more than 4 weeks, the possibility of contamination cannot be ruled out.

Recently a number of distinct apoB isoproteins have been found in plasma from rats ${ }^{19}$ and humans. ${ }^{20}$ Kane et $a l^{20}$ have demonstrated the presence in human plasma of liver derived apoB, with an apparent molecular weight of 549000 (apoB-100), and a gut derived species with a molecular weight of 264000 (apoB-48) secreted in association with chylomicrons. In addition, the cleavage products of apoB-100, apoB-74, and apoB-26 may often be detected in plasma from normal subjects. Polyacrylamide electrophoresis of plasma from the proband failed to reveal any apoB species other than apoB-100. Considering the minute amounts of apoB present, however, it is not possible to draw firm conclusions concerning the secretion of apoB-48. Evidence that apoB-48 is more rapidly cleared from the plasma than is apoB-100, ${ }^{21}$ and the temporal association of apoB-48 with food intake, makes its detection inherently less likely.
Our data suggest that the patients with homozygous HBLP are capable of synthesising: normal apoB. While firm conclusions will ultimately $\overrightarrow{\vec{s}}$ depend upon more detailed structural studies, it is attractive to regard HBLP as being the result of failure of secretion or of a regulatory abnormality. $\frac{\overline{\bar{p}}}{\bar{p}}$ This proposal is in accord with the report of Sigurdsson et $a l^{22}$ that the apparent apoB synthetic rate is markedly reduced in hypobetalipoprotein- $\omega$ aemic subjects, which they attributed to impaired $\overrightarrow{0}$ secretion of very low density lipoprotein. A failureof secretion could, theoretically, be confirmed by $\vec{\omega}$ demonstrating the presence of apoB specific immunofluorescence in the intestinal mucosal cellso or hepatocytes of the proband; the absence of 0 immunoreactive apoB in intestinal biopsy materialic has been described in patients with ABLPR. ${ }^{23} \dot{\infty}$ Unfortunately permission to biopsy the proband was refused and thus the possibility of a failure of synthesis could not be excluded.

It is appropriate to speculate whether the presence of minute quantities of apoB in the plasma of patients with homozygous HBLP can account for $\vec{\bullet}$ the differences in clinical presentation when compared with $\mathrm{ABLP}_{\mathbf{R}}$. It is possible that the actual ${ }^{\circ}$ rate of apoB secretion or fat absorption in theo former condition is greater than suggested by the plasma levels, owing to rapid removal by the pre-sumably high receptor content of cells in contact $\frac{0}{\mathbb{Q}}$ with apoB depleted plasma. This possibility may account in part for the discrepancy, noted by $\overrightarrow{\overrightarrow{0}}$ Illingworth et $a l^{6}$ in a 16-year-old girl with 3 homozygous HBLP, between the negligible $(0.5 \%)$ 导 absorption of $\left[{ }^{3} \mathrm{H}\right]$-cholesterol determined by blood? radioactivity levels and the 24 to $30 \%$ difference 3 between ingested and faecal $\left[{ }^{3} \mathrm{H}\right]$-cholesterol. Eveno reduced secretion coupled with rapid turnover could $\overline{3}$ allow for the greater transport of putatively. protective factors, such as vitamin E, in amounts sufficient to retard the development of the characteristic ocular and neurological pathology을 associated with ABLPR.

\section{References}

1 Herbert PN, Gotto AM, Fredrickson DS. Familial lipoprotein deficiency. In: Stanbury JB, Wyngaarden JB, N Frederickson DS, eds. Metabolic basis of inherited disease.
4th ed. New York: McGraw-Hill, 1978;544-88.

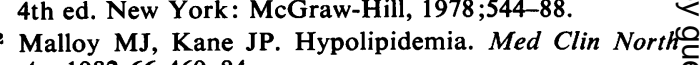
Am 1982;66:469-84.

3 Salt HB, Wolff OH, Lloyd JK, Fosbrooke AS, $\stackrel{\text { ? }}{+}$ Cameron AH, Hubble DB. On having no beta-lipoprotein. A syndrome comprising abetalipoproteinaemia, acantho- $\bar{O}$ cytosis and steatorrhoea. Lancet 1960;ii:325-9.

4 Cottrill C, Glueck CJ, Leuba V, Millett F, Puppione D, $\frac{\stackrel{P}{\Phi}}{\mathscr{D}}$ Brown WV. Familial homozygous hypobetalipoprotein-@ aemia. Metabolism 1974;23:779-91. 
5 Biemer JJ, McCammon RE. The genetic relationship of abetalipoproteinaemia and hypobetalipoproteinaemia: a report of the occurrence of both diseases within the same family. $J$ Lab Clin Med 1976;85:556-65.

6 Illingworth DR, Connor WE, Buist NRM, Jhaveri BM, Lin DS, McMurry MP. Sterol balance in abetalipoproteinaemia: studies in a patient with homozygous hypobetalipoproteinaemia. Metabolism 1979;28:1152-60.

7 Bassen FA, Kornzweig AL. Malformation of the erythrocytes in a case of atypical retinitis pigmentosa. Blood 1950;5:381-7.

8 Malloy MJ, Kane JP, Hardman DA, Hamilton RL, Dalal KB. Normotriglyceridaemic abetalipoproteinaemia. J Clin Invest $1981 ; 67: 1441-50$

9 Manual of laboratory operations of the lipid research clinics program. Vol 1. Lipid and lipoprotein analysis. DHEW Publication, May 1974;75:629.

10 Steele BW, Koehler DF, Azar MM, Blasokowski TP, Kuba K, Dempsey ME. Enzymatic determination of cholesterol in high density lipoprotein fractions prepared by a precipitation technique. Clin Chem 1976;22:98-101.

11 Friedewald WT, Levy RI, Fredrickson DS. Estimation of the concentration of low density lipoprotein cholesterol in plasma. Clin Chem 1972;18:499-502.

12 Kates M. Techniques of lipidology, In: Work TS, Work $\mathrm{E}$, eds. Laboratory techniques in biochemistry and molecular biology. Amsterdam: North Holland/Elsevier, 1972:352,355-6.

13 Laemmli UK. Cleavage of structural proteins during the assembly of the head of bacteriophage T4. Nature 1970; 227:680-5.

14 Laurell CB. Quantitative estimation of proteins by electrophoresis in agarose gel containing antibodies. Anal Biochem 1966;15:45-52.

15 Cooper RA, Durocher JR, Leslie MH. Decreased fluidity of red cell membrane lipids in abetalipoproteinaemia. $J$ Clin Invest 1977;60:115-21.

16 Anderson CE, Brokhattingen K, Lous R. Familial hypobetalipoproteinaemia in 9 children diagnosed as the result of cord blood screening. Arch Dis Child 1979;54:691-4.

17 Glueck CJ, Mellies MJ, Tsang RC, Steiner PM, Stein EA. Neonatal hypobetalipoproteinaemia. Pediatr Res 1978; 12:665-8.

18 Albers JJ, Cabana VG, Hazzard WR. Immunoassay of human plasma apolipoprotein B. Metabolism 1975;24: 1339-50.

19 Krishnaiah KV, Walker LF, Borensztajn J, Schonfeld G, Getz GS. Apolipoprotein B variant derived from rat intestine. Proc Natl Acad Sci USA 1980;77:3806-10.

20 Kane JP, Hardman DA, Paulus HE. Heterogeneity of apolipoprotein B: isolation of a new species from human chylomicrons. Proc Natl Acad Sci USA 1980;77:2465-9.

21 Wu AL, Windmueller HG. Variant forms of plasma apolipoprotein B. Hepatic and intestinal biosynthesis and heterogeneous metabolism in the rat. J Biol Chem 1981; 256:3615-8.

22 Sigurdsson G, Nicoll A, Lewis B. Turnover of apolipoprotein B in two subjects with familial hypobetalipoproteinaemia. Metabolism 1977;26:25-31.

23 Glickman RM, Green PHR, Lees LS, Lux SE, Kilgore A. Immunofluorescence studies of apolipoprotein B in intestinal mucosa. Absence in abetalipoproteinaemia. Gastroenterology 1979;26:288-92.

Correspondence and requests for reprints to Professor G M B Berger, Department of Chemical Pathology, Red Cross War Memorial Children's Hospital, Rondebosch 7700, Cape, South Africa. 